\title{
The Exploration of Workshop Teaching Mode for Architectural Design Specialty in Universities
}

\author{
Juan Ren * \\ Architecture School \\ Chang'an University \\ Xi'an, China
}

\author{
Peiyao Li \\ Architecture School \\ Chang'an University \\ Xi' an, China
}

\author{
Qibo Liu \\ Architecture School \\ Chang'an University \\ Xi'an, China
}

\begin{abstract}
The cultivation of innovative thinking has always been the focus of architectural design education. How to guide students to break the solidification of thinking and stimulate the initiative of creation is always the direction that educators continue to explore. As a popular new design teaching mode, workshop provides students and teachers with multi-level, crossdisciplinary and open teaching activities. In this paper, taking one architectural joint workshop in Chinese university as example, authors intend to provide relevant practical experience of the training methods to inspire students' innovative thinking in the design.
\end{abstract}

Keywords-workshop; design education; public sphere; innovative thinking

\section{INTRODUCTION}

As current popular teaching model, design workshop focuses on thematic research. It integrates teaching and academic activities such as theoretical lectures, practical surveys, design drawings and exhibitions, as well as providing students and teachers with multi-level and cross-field open teaching activities to stimulate design innovation [1]. This paper introduces the teaching process and content of one architectural joint workshop which focuses on the public sphere, and discusses the benefits of workshop educational mode for architectural design in Chinese university. It also intends to provide reference and mode for cultivating students' innovative thinking.

This workshop takes "Gap of public sphere - research for the private domain in public scenarios" as theme. There are three teaching stages within 15 days for this workshop, including theoretical courses, students' research, design and discussions. It is also intensive training to promote students' abilities of extended mind, design expression, strain capacity, teamwork, etc.

First of all, teachers and students intend to practice a new design method which different from the traditional common curriculum design: starting from the social phenomenon and basic theory of sociology, leading students to establish their own program logic of "public domain” and "private domain" based on the investigation for urban public sphere, eventually individual original design is deduced. During this teaching process, research, design and analysis appear alternately to promote design concept, which shall evolve into the design scheme with architectural format. It is an opening teaching process enables students to spontaneously recognize the essential of design and inspire innovation ability [2].

\section{TEACHING PROCESS}

A. Phase 1. Investigating a public space in the city; and then, confirming its location, status of people's activities, as well as the relationship between this public space and city

The teaching target mainly focuses on training students to arrange and analyze the information on urban spatial phenomenon. Through the field research and analysis of media releases, students need to build their own frameworks for the social context of this research objects. In this phase, students have understood the role of research object in the public space from the social phenomenon perspective, and then sorted the information about social phenomenon by their own ways, finally expressed their opinions. Based on the research about urban space, sociology and other theories, students are guided to sort out their own understanding about public domain, local domain, and public atmosphere, then confirmed the investigated site to record and study in depth. During the process, students have explored the phenomenon and found a certain basis or background for the emergence of the phenomenon.

At this stage, teacher guided students to start design from the perspective of phenomenology and sociology, and leaded them to break the inertial mindset that students always want to drive in and analyze the architectural space composition and design strategies after investigating somewhere. Based on these works, students intend to find the connection between place 
and people in the public and private domains in the city, or to know what happens in these spaces. And then they shall focus on the objective statements rather than judgments. This research method breaks limitations of students' design thinking due to the inherent values to judge certain behaviors or phenomena in the very early design thinking stage.

For example, the blocks in old city are seriously lacking public space. During the investigation, students found that a large number of people lay down in the street or occupied road to communicate with each other. At first discuss, some students have taken time to criticize this phenomenon. Teacher guided them to explore the reason for these phenomena from the perspective of architecture and sociology, tried to make students break the inherent thinking to discuss the impact of people's activities in the urban space. One student have written in the personal design statement is that "The public activities on the roadside are like a stage play, and everyone acts as a protagonist. My design aims to create a stage for them, and give them the right to interpret their own story on the stage. Someone may ask me that their building has already provided them with a stage, why you rebuilt another again? Though the investigation, I think these backgrounds can't make people feel comfortable and safe indeed, so I have to create a stage which really satisfies their needs [3]. ” Due to avoiding the rigidity of the initial thinking, this student finally found the entry point of design.

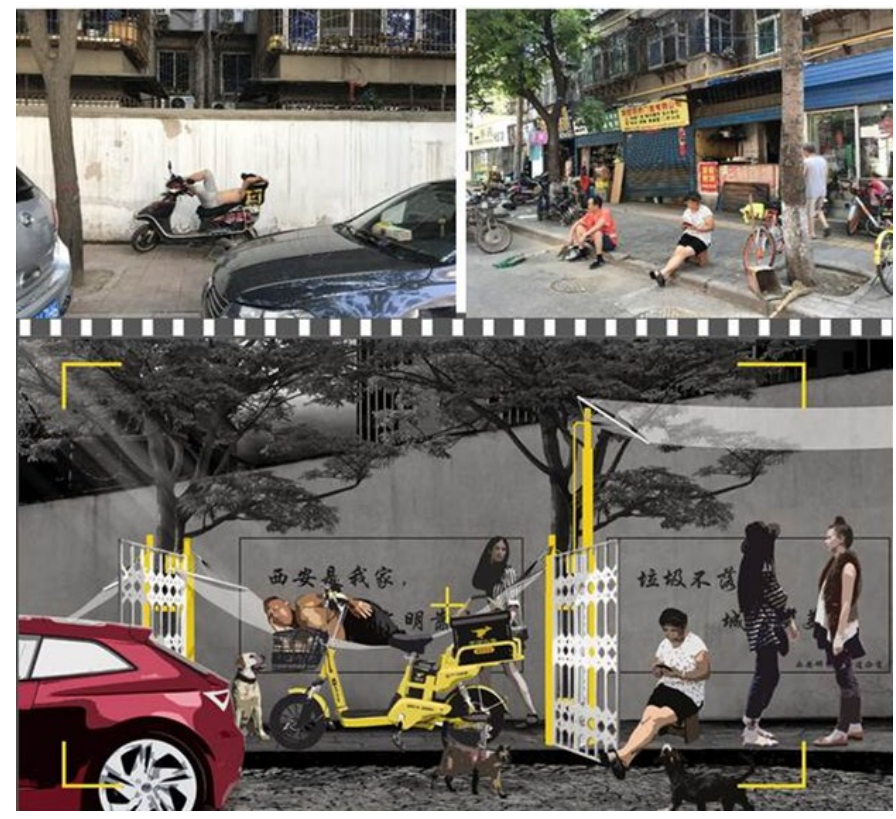

Fig. 1. People's behavior in old blocks and corresponding design installations .(drawing by Li Peiyao)

\section{B. Phase 2. Using the collage and diagram methods to illustrate the phenomenon which happens in investigated site in architectural pattern}

According to the established track of people in public space, students screened certain main spaces out. On the one hand, they recorded these spaces by photograph, video, axonometric redrawing and graphical analysis; on the other hand, they stacked these scattered spaces onto the city map to find the relationship between public sphere and users. In this process, students involved needed to carry out many records of that people have done and where are they. The state of people using the public space as the ultimate goal of the entire study realizes the materialization of theoretical and phenomenal research.

At this stage, students are required to draw the typical urban public space which they have chosen on the basis of the first stage. Due to the limitation of some place, accurate shooting or data measurement is not possible during the survey. It requires students to use a variety of research and material collection to estimate spatial scales and record effectively the activity of the crowd. When they begin to make detailed drawings, students give priority to use CAD and Sketchup software to integrate the spatial modules of survey, as well as draw the area map and the axonometric map. This part work is not just a simple restoration of the building, but requires students to think the most representative elements in a variety of activities occurring at the same place in different periods and complete the fusion. The completed type is the typology building after refining. In the axonometric drawing phase, teacher have trained students to use the characters and detailed objects to reflect the events occurring in the space, to express the use and atmosphere of the building space, and to increase the readability and interest of the drawings with graphic language .

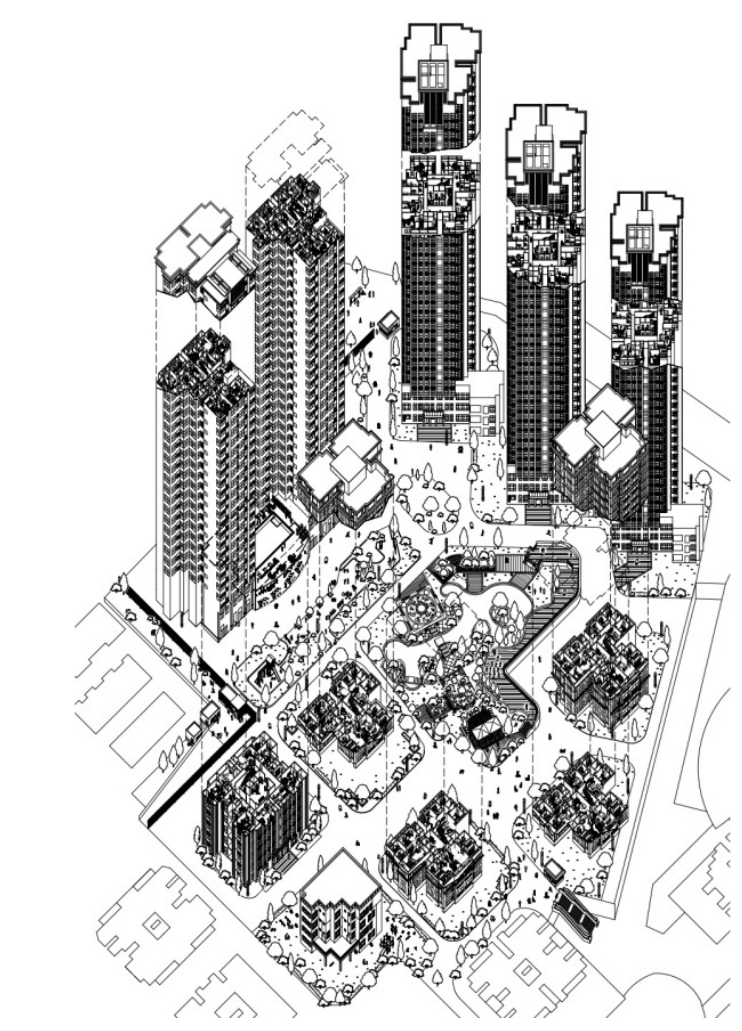

Fig. 2. Expression of investigation research: public space in a new residential community.(drawing by Fang Yunshang, Yin Tiantian and Wang Kunqi) 
C. Phase 3. Determining the design theme and subject, complete design and logic description of the concept structure

As the final stage of this workshop, the task is to guide each student to develop his own thinking of the urban public sphere and construct the design based on the preliminary work. The design can be a direct practical device, a conceptual model or the assumption of the building. In the meanwhile, students are also required to combine the theoretical with current research results to compile a description of operational logic of the design. The teaching target is lead ing students to express their own reflections on the living conditions of the people in different public spaces in the current city with architectural language, and also put forward the diversity relationships between people, space, buildings and cities.

Different from the previous teamwork, this stage mainly focused on training each student's individual thinking. For students, one of the main challenges is to find the point of penetration in a short time and complete the design independently. It is necessary to mobilize the enthusiasm of students' thinking and encourage innovative exploration. Firstly, the teacher guided students to participate in brainstorming on the basis of previous research, to organize multiple rounds of discussion, and encourage students to propose diverse solutions as much as possible. At this stage, the design concepts have put forward by the students presents a rich variety: the urban furniture designed according to the current situation of old blocks, the inductive integration of the messy residential courtyards, the individualistic landscape sketches and so on. In the beginning of design concepts, teachers have paid attention to give students enough time to present their ideas and conducted open discussions. Teachers respected the original thinking of the students, and avoided some "authority interference" on these ideas. This interactive teaching method effectively shortens the time for students to refine a large number of theories and design elements, promotes the atmosphere of fair communication in the teaching process. It also benefits for students to be proactive in completing innovative exploration and design in a limited time.
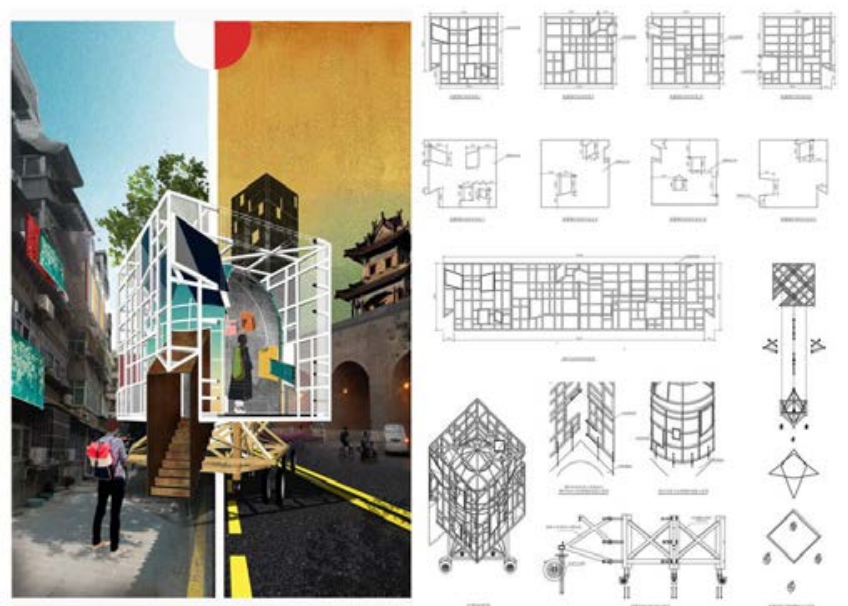

Fig. 3. Individual design: community memory capture station.(drawing by Wang Haonan)

\section{BENEFITS}

Compared with traditional class, workshop focuses more on the exploration of a certain topic. Research, discussion and other teaching activities in workshop are more flexible and diversified. Due to the basic requirements of syllabus, the content of classroom teaching, the methods and steps of students' design, the expression of achievements and other aspects inevitably have certain solidification convergence in traditional design teaching classroom. As a complementary model in design teaching, workshop provides more diversified ideas and methods for teachers with different research backgrounds to guide students in the process of design and creation exploration. In the process of learning and communication, students can also broaden their knowledge range, promote their initiative and creativity in independent learning, improve their professional quality and study results. On the other hand, the setting time of workshop is concentrated with strong learning intensity. In this workshop, the average working time of teachers and students involved is more than ten hours per day. This is a great challenge which has high requirements on students' learning and resilience to pressure. Students and teachers need to cooperate and coordinate with each other in order to quickly work best.

In addition, the presentation and expression of phase results are also very important in this workshop. This method clarifies the key points of work in different stages, effectively controls the content and direction of the design process in the relatively free creativity display, and also let students and teachers adjust in time. The phase summary work pattern shall guarantee the quality of the final design results in a short period of time.

\section{SUMMARY}

The implementation of workshop shall stimulate the creative thinking of participating teachers and students, improve students' initiative in learning and exploration, and extend the diversity of architectural design teaching and research activities. Although the short-term workshop cannot completely replace the traditional classroom teaching mode currently, as an extension and supplement of classroom teaching, workshop can bring better teaching and learning effects, especially provide practical value and certain promotion for the architectural design teaching research.

\section{ACKNOWLEDGMENT}

This work was carried out by Architecture School of Chang'an University and Monolith Architects.

We gratefully acknowledge the invaluable contribution of Mao Lei and all the participated students in the workshop.

\section{REFERENCES}

[1] Zhang Xiaorui, Zheng Xianyou, A Study on Architectural Professional Teaching Mode Based on WORKSHOP, 2009, 18(3):137-139. In Chinese 
[2] Chen Yan, Hu Shenjian, Tang Jian, Research on the Teaching Mode of WORKSHOP Co-design in Environmental Design Specialty, Architecture \& Culture, 2017(3):88-89. In Chinese

[3] Li Peiyao, The personal statement for "The Gaps for Public Space”, 2018. In Chinese

[4] De Waal, Martijn. The City as Interface: How Digital Media Are Changing the City. NAI Publishers.2014.
[5] Cai Jianguo, Feng Jiana, Ren Zheng, Research on trans-disciplinary cooperation mode based on workshop, Journal of Architectural Education in Institutions of Higher Learning, 2016(6): 54-60. In Chinese

[6] Alekseevna N G, Andreevna B Y, Yuryevna A A. Interactive Forms of Open Scientific and Educational Workshop [J]. 2014(6):15-25. 